\title{
Re: The efficacy and safety of ureteroscopy for ureteral calculi in pregnancy: our experience in 32 patients
}

\author{
Abdulkadir Tepeler • Abdullah Armağan · Zafer Doğan • \\ Mehmet Yılmaz $\cdot$ Mesrur Selçuk Sılay
}

Received: 7 January 2012 / Accepted: 18 January 2012 / Published online: 2 February 2012

(C) Springer-Verlag 2012

We read the retrospective study presenting the series on ureteroscopy (URS) using for urolithiasis in pregnant women with great interest [1]. Although many studies have published about the feasibility and safety of URS in pregnant women in recent years [2-5], this is the largest series. I applaud the authors for managing 32 pregnant patients who had obstructive symptoms related with ureter calculi $(n: 27)$ and non-calculous conditions ( $n: 5)$.

Although the safety of URS for ureteral stones in pregnant patients is not significantly different from the safety of that procedure in non-pregnant patients [5], in fact it causes anxiety to the each of patient and surgeon. Perioperative anesthesia management of pregnant women during obstetric or non-obstetric surgery is more stressful than non-pregnant women because of maternal physiological changes during pregnancy, diseases specific for pregnancy and taking care of both pregnant and fetus [6].

Endoscopic procedures on pregnant women are performed with no fluoroscopic control to avoid the deleterious effects of radiation exposure on her and the fetus. All of the endoscopic procedures performed on pregnant without fluoroscopic imaging require advanced surgical skills, special care, and experience. The usage of inverted fluoroscope's

A. Tepeler $(\bowtie) \cdot$ A. Armağan $\cdot$ M. S. Silay

Department of Urology, Faculty of Medicine,

Bezmialem Vakif University, Adnan Mendres Bulvarı,

Fatih, Istanbul, Turkey

e-mail: akadirtepeler@yahoo.com

\section{Z. Doğan}

Department of Anesthesiology, Faculty of Medicine,

Bezmialem Vakif University, Istanbul, Turkey

M. Yilmaz

Department of Obstetrics and Gynecology, Faculty of Medicine, Atatürk University, Erzurum, Turkey
$\mathrm{C}$-arm and thyroid collars to shield the uterus was previously reported to protect the fetus from the direct radiation exposure [7]. Ultrasonography (US) or Doppler US is the safest and X-ray free imaging modality used as guidance for the diagnosis of ureteral calculi or endoscopic treatment [8]. In the study, the authors have performed all procedures with direct visualization. No information is added if they felt any difficulty during the manipulations such as ureteral balloon dilation or Double-J stent or guide-wire insertion.

\section{References}

1. Bozkurt Y, Penbegul N, Soylemez H, Atar M, Sancaktutar AA, Yildirım K, Sak ME (2012) The efficacy and safety of ureteroscopy for ureteral calculi in pregnancy: our experience in 32 patients. Urol Res. doi:10.1007/s00240-011-0454-y

2. Isen K, Hatipoglu NK, Dedeoglu S, Atılgan I, Caça FN, Hatipoglu N (2011) Experience with the diagnosis and management of symptomatic ureteric stones during pregnancy. Urology [Epub ahead of print]

3. Polat F, Yeşil S, Kıraç M, Biri H (2011) Treatment outcomes of semirigid ureterorenoscopy and intracorporeal lithotripsy in pregnant women with obstructive ureteral calculi. Urol Res 39(6):487-490

4. Rana AM, Aquil S, Khawaja AM (2009) Semirigid ureteroscopy and pneumatic lithotripsy as definitive management of obstructive ureteral calculi during pregnancy. Urology 73(5):964-967

5. Semins MJ, Trock BJ, Matlaga BR (2009) The safety of ureteroscopy during pregnancy: a systematic review and meta-analysis. J Urol 181(1):139-1343

6. Vasquez DN, Estenssoro E, Canales HS, Reina R, Saenz MG, Neves AVD, Toro MA, Loudet CI (2007) Clinical characteristics and outcomes of obstetric patients requiring ICU admission. Chest 131(3):718-724

7. Cocuzza M, Colombo JR Jr, Lopes RI, Piovesan AC, Borges Mesquita JL, Srougi M (2010) Use of inverted fluoroscope's C-arm during endoscopic treatment of urinary tract obstruction in pregnancy: a practicable solution to cut radiation. Urology 75(6):1505-1508

8. Elgamasy A, Elsherif A (2010) Use of Doppler ultrasonography and rigid ureteroscopy for managing symptomatic ureteric stones during pregnancy. BJU Int 106(2):262-266 